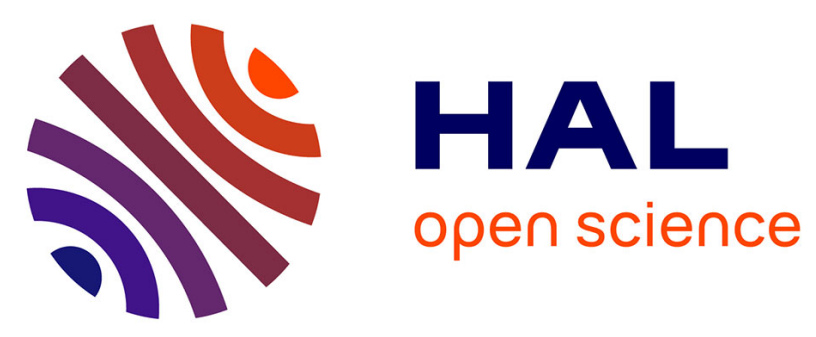

\title{
Concepts and methods for analysing the role of Information and Communication tools (IC-tools) in Social Learning processes for River Basin Management
}

Pierre Maurel, Marc Craps, Flavie Cernesson, Richard Raymond, Pieter Valkering, Nils Ferrand

\section{To cite this version:}

Pierre Maurel, Marc Craps, Flavie Cernesson, Richard Raymond, Pieter Valkering, et al.. Concepts and methods for analysing the role of Information and Communication tools (IC-tools) in Social Learning processes for River Basin Management. Environmental Modelling and Software, 2007, 22 (5), pp.630-639. 10.1016/j.envsoft.2005.12.016 . hal-01575625

\section{HAL Id: hal-01575625 \\ https://hal.science/hal-01575625}

Submitted on 19 Nov 2019

HAL is a multi-disciplinary open access archive for the deposit and dissemination of scientific research documents, whether they are published or not. The documents may come from teaching and research institutions in France or abroad, or from public or private research centers.
L'archive ouverte pluridisciplinaire $\mathbf{H A L}$, est destinée au dépôt et à la diffusion de documents scientifiques de niveau recherche, publiés ou non, émanant des établissements d'enseignement et de recherche français ou étrangers, des laboratoires publics ou privés. 


\title{
Concepts and methods for analysing the role of Information and Communication tools (IC-tools) in Social Learning processes for River Basin Management
}

\author{
Pierre Maurel $^{\mathrm{a}, *}$, Marc Craps ${ }^{\mathrm{b}}$, Flavie Cernesson ${ }^{\mathrm{a}}$, Richard Raymond ${ }^{\mathrm{a}}$, \\ Pieter Valkering ${ }^{\mathrm{c}}$, Nils Ferrand ${ }^{\mathrm{a}}$ \\ ${ }^{a}$ Cemagref/ENGREF, 500 rue JF Breton, 34093 Montpellier Cedex 5, France \\ ${ }^{\mathrm{b}}$ Centre for Organisational and Personnel Psychology, K.U. Leuven, Tiensestraat 102, B-3000 Leuven, Belgium \\ ${ }^{\mathrm{c}}$ ICIS, University of Maastricht, P.O. Box 616, 6200 MD Maastricht, the Netherlands \\ Received 20 October 2005; received in revised form 15 November 2005; accepted 15 December 2005 \\ Available online 21 April 2006
}

\section{Introduction}

\subsection{The Water Framework Directive and public} participation

In Europe, the Water Framework Directive (WFD) 2000/ 60/EC of 23 October, 2000 established a framework for Community action in the field of water policy. The key objective of the directive is to achieve by 2015 a "good water status" for all European surface and underground waters. One of the five main instruments that will be used to reach this objective is Public Participation (PP).

The main article of the WFD concerning PP (Article 14) states:

"Member States shall encourage the active involvement of all interested parties in the implementation of this Directive, in particular in the production, review and updating of the river basin management plans."

But what does PP and "active involvement of interested parties" mean and what does it imply? PP can generally be defined as a process by which citizens, as individuals or 
collectively, are engaged in a planning or decision that impacts their livelihoods or environment. Several benefits but also

drawbacks can be expected from PP, as described in a recent synthesis (Drafting Group, 2002; Mostert, 2003). This synthesis also shows that PP is necessary but has to be organised in order to make it work, especially in terms of the types of out-

comes expected and which elements of 'the public' to involve.

Different types of participation that refer to different levels of involvement are commonly conceptualised as Arnstein's ladder of participation (Arnstein, 1969). Article 14 of the WFD recognises the need for three types of participation in river basin planning: information supply; consultation (plans and options are made available for comments); and active involvement. Of these active involvement is both the most challenging and the least well-explored aspect.

The terms "stakeholder" or "interested party" are often

used in relation to active involvement. Stakeholders may be any person, group or organisation with an interest or "stake"

in an issue either because he/she will be affected or because he/she may have some influence on the outcome. The guidance document for PP related to the WFD (Drafting Group, 2002) proposes a typology of stakeholders involved in River Basin Management (RBM): professionals, authorities and elected people, local groups and non-professional organised entities and finally, individual citizens, farmers and companies representing themselves.

\subsection{Social Learning in the HarmoniCOP project}

The EU research project HarmoniCOP ${ }^{1}$ studies a new approach of PP called Social Learning (SL), which promotes collective actions within social networks (Craps, 2003). The conceptual framework of SL is represented in Fig. 1. From a SL point of view, River Basin Management (RBM) is considered a social/technical participatory process [2]. This process includes both a social-relational activity (part 2.2 of Fig. 1) (e.g. the generation of social capital, the development of new social practices) and a complex technical task [2.3]. These two aspects of reality cannot be separated. SL also corresponds to the outcomes of this process, which are both technical and relational [3]. It takes place in a specific context [1] in terms of the governance system (actors, regulation and cultural norms) and the river basin environment. This context can be affected in turn by the outcomes [4].

A collective problem solving approach requires that actors meet each other to develop new insights through relational practices [2.1]. The quality of these relational practices is fundamental from a SL perspective: the different stakeholder groups in a river basin learn to take into account the diversity of interests, of mental frames, of disseminated information and knowledge, to resolve better the complex issues related to the RBM.

By a process called framing/reframing actors necessarily perceive and intervene in a domain like RBM from a particular

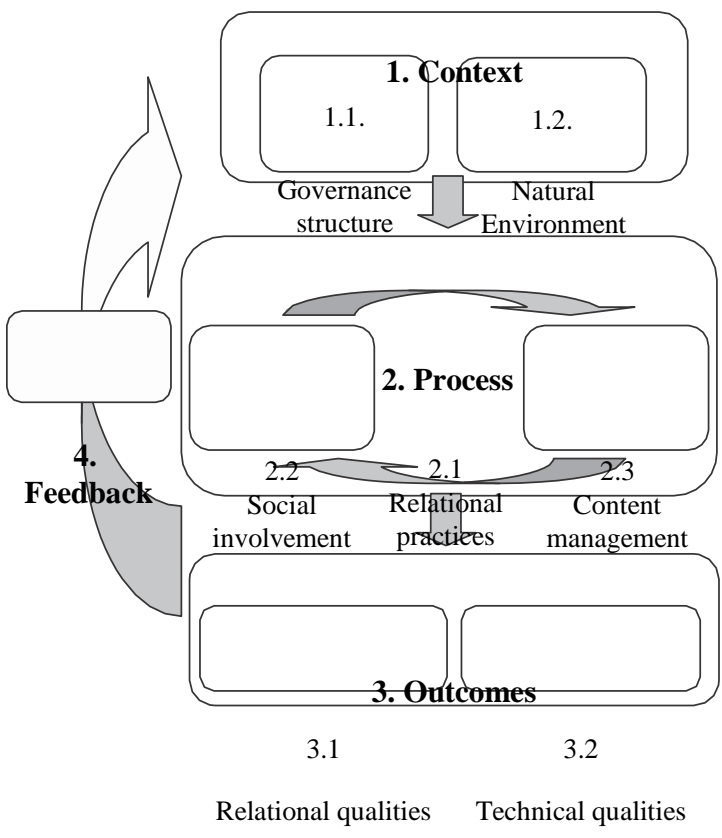

\footnotetext{
1 HarmoniCOP: Harmonising COllaborative Planning. http://www. harmonicop.info/
} 
Fig. 1. Graphical framework of the Social Learning concept in HarmoniCOP.

perspective and with a particular action logic (Dewulf et al., 2005; Lewicki et al., 2003). Because of their different experiences or professional backgrounds and their different interests actors may frame the issues and solutions to be considered in relation to RBM in very diverse ways. Through this framing they draw boundaries around a domain not only in a geographical sense (defining geographical limits) but also in a physical sense (selecting certain content issues as relevant), in a social sense (restricting legitimacy to certain actors) and in a psychological sense (determining who identifies with or is identified with the river basin and planning efforts). SL constitutes then a process of reflective framing and re-framing through which multi-actor groups by integrating, linking or alternating between different frames may come to generate better quality solutions for the problems identified in a river basin (Craps, 2003).

\subsection{IC-tools as facilitating mechanisms for PP and SL}

The SL approach to RBM raises the crucial issue of information design, storage and retrieval and communication between state's institutions and stakeholders in ways that are relevant for them and that allows collective learning (Rool, 2004; Woodhill, 2004). Effective communication is all the more essential as PP is highly time-consuming due to the increasing number of interactions and the difficulties to combine expert and non-expert knowledge, even if this process is fruitful (Pahl-Wostl, 2002).

Within the HarmoniCOP project, the term "information" is used as a result of the processing of data or knowledge or points of view in a given context for a specific purpose.

The term "communication" is defined here as social interaction through messages (Fisker, 1990). This is much more than the exchange of information, but it is also a means to reflect and reinforce social relations or "communities". New communication patterns can help to build up new communities. Within these communities, new representations and new "meanings" of reality can develop (Wenger, 1998). 
Based on these definitions, we consider an Information and Communication Tool (IC-tool) as an artefact, device or software, that can be seen and/or touched, and which is used in a participatory process to facilitate Social Learning. It supports interaction between stakeholders through two-way communication processes.

Based on a literature review and a comparison of usage situations in the different countries involved in HarmoniCOP, we propose the list of IC-tools shown in Table 1.

\section{Criteria of categorisation}

We have identified four main criteria to categorise the usefulness of IC-tools for those who will have to organise a WFD $\mathrm{PP}$ process in practice.

\subsection{Direction of communication}

This criterion allows determining the attractiveness of an ICtool according to the fact that the communication between organisers and stakeholders is directed top-down (from the leading team to the stakeholders and the general public), bottom-up or both (bi-directional).

\subsection{Public size}

We have distinguished two types of public size where ICtools can be used to support communication. This distinction has a real importance to characterise the context of use of each tool. The first type corresponds to small working groups (single or multiparty) where people generally meet face-to- face or exchange through specific tools. In this case, technical staff can directly manipulate the tools and adapt their use to the situation or provide assistance to the users upon request. The second type corresponds to the general public. In this case, the relational events are space-time distributed. This means that interactions take place between a large number of individuals, residing at different locations, over longer pe- riods of time. Such interactions are typically achieved via

Table 1

List of IC-tools

Artefacts/devices Software

- Questionnaire

- Maps ${ }^{\mathrm{a}}$, photos, images

- 3D scale model ${ }^{\mathrm{a}}$

- Conceptual models

For data base

For systems dynamic

- Cognitive mapping tool ${ }^{\mathrm{a}}$

- Actors mapping tool ${ }^{\mathrm{a}}$

- Management of comments

- Role playing game ${ }^{a}$

- Interactive white board ${ }^{\mathrm{a}}$

- Board game mailings and the world-wide web. People interact indirectly through artefacts: letter, e-mail, etc. In this case, face-to-face technical assistance or real-time adjustments are not possible any more. These tools are often more closed than the first ones.

\subsection{Usage purpose}

We have identified four main purposes.

\subsubsection{Management of information and knowledge}

The corresponding IC-tools aim to store, retrieve, analyse, display and disseminate information. This is one of the usual functions of most IC-tools but in the context of SL and PP, it raises important questions. How does one deal with the sharing of information between actors belonging to different communities of knowledge and of practice with multiple perspectives, points of view, vocabularies, skills? How are uncertainties addressed? How to keep the memory of relational events and make it accessible and understandable to non-participants? How to respect the confidentiality rules that have been adopted? How to assure well balanced, or at least well accepted informational power and resources among the actors? What are the influences of the distribution of informational resources among the actors on their relation?

\subsubsection{Perspective elicitation}

Here, the IC-tools help to elicit frames and behaviours of stakeholders, to make them explicit to the others. This may be the most challenging and innovative relational function of IC-tools to contribute to SL. However this function depends not only on the intrinsic properties of the tool but also on the way it is designed and used within "transitional spaces" (Craps et al., 2004) that cross the boundaries between commu- nities of knowledge and of practice. To be able to fulfil this function, an IC-tool should have all or part of the properties of what Star and Greisemer (1989) call boundary objects and Vinck and Jeantet (1995) call intermediary objects.

\subsubsection{Interaction support}

These IC-tools are designed to support the interactions between actors, to improve communication and bring the indi-

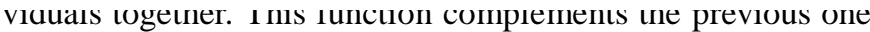
and raises also central issues related to SL (inclusion or exclusion of participants, support for framing/reframing activities, etc.). It depends also on the way tools are implemented and used by the participants.

\subsubsection{Simulation}

The scope of IC-tools here is to simulate the dynamics of $\mathrm{RB}$ systems to assess environmental, and/or technical and/or economical and/or social-cultural impacts of RBM. Typical examples of simulation tools are Decision Support Systems 
a IC-tool described by an index card in (Maurel, 2003).

(DSS), Integrated Assessment models, and qualitative modelling techniques. 


\subsection{Phases in the PP process}

This criterion refers to the phase of PP in which the tool can be used. We have chosen to comply with the four phases proposed in the EU guidance document for Public Participation: (1) starting organisation, (2) actors and context analysis, (3) diagnosis of the situation, (4) search for solutions, and two additional phases: (5) implementation and (6) follow-up and feedback.

A first qualitative classification of IC-tools using the four criteria previously described and a three level scale (0: low interest, 1: medium interest, 2: high interest) is presented in (Maurel, 2003).

\section{Framework of analysis}

In this section we describe a framework of analysis to explore IC-tool impact on participatory and SL processes. This framework is based on a joint approach of psychologists and engineering sciences experts. It was empirically tested in 2004 and 2005 in a number of historical and real-time case studies (HarmoniCOP WP5).

The evaluation criteria are derived from HarmoniCOP discussions and from literature on the evaluation of PP (Webler et al., 2001), on the evaluation of tools (Ubbels and Verhallen, 2000), on the factors of technology acceptance and usability (Legris et al., 2003), and on participation in integrated assessment and modelling for the environment (Pahl-Wostl, 2002).

Based on these criteria, a check list, with some basic explanation of the underlying assumptions, was produced called "Social Learning Pool of Questions" (PoQ) (Craps and Maurel, 2003).

The SL PoQ consists of three layers:

What: A list of general questions, summarising the main issues that have to be considered in relation to $\mathrm{SL}$ in RBM. The structural order of the questions follows the conceptual framework that is demonstrated in Fig. 1.

Why: A short explanation of the underlying assumptions of these questions.

How: Examples of concrete and clear questions that can be used in interviews with stakeholders.

A charting procedure, part of the SL PoQ, facilitates the collection and analysis of information (Ferrand et al., 2004).

The SL PoQ includes three perspectives for analysing ICtools: their technical characteristics and usage situation (described in Section 3.1), their impact on PP and SL (Section 3.2) and their usability as perceived by the users (Section 3.3).

\subsection{IC-tools characteristics and usage situation}

A first series of factual criteria concerns the usage situation of IC-tools for each relational event in the PP process:

list of IC-tools that have been used; phase(s) in the process; main usage purposes (both for relational and substantive tasks);

relations between the actors and the IC-tool: who promoted or prevented the use of the tool, who manages it, who provides the data/information/knowledge, who has access to it or to its informational content?

Then, for each IC-tool that was identified, a second series of criteria addresses the technical characteristics of the tool. These criteria are synthesised in an IC-tool index card divided into 5 main sections:

e General characteristics: Each tool is characterised by its type, its complexity, its availability, and its current stage of development.

e Usage purposes: The IC-tool uses are defined according to the context of the participatory process and the relational and/or substantive tasks to be performed. Four main usage purposes (with the corresponding functionalities and conditions of use) are a priori proposed: information and knowledge management, interaction support, perspective elicitation, simulation (see Section 2.3). These functionalities determine the potentials of the tool in a given context, even if some gaps with the reality may be observed for several reasons: restrictive use, use for other purposes, unpredictable secondary effect, tool usability perceived differently by non-expert stakeholders.

e Sustainability: Some conditions are necessary to guarantee a minimal sustainability of the tool: direct or indirect use by the actors, availability of use support, degree of open- ness, and management of the monitoring/reporting or tracability.

e Informational output description: Content and formal aspects.

e Uncertainties management: The information is rarely an original quantitative data set. There are numerous sources of uncertainty, particularly in ecosystem management, linked to variability (of natural processes, human behaviour, social dynamics, etc.) and to limited knowledge (lack of observations, practically immeasurable data, etc.) Therefore, an important function of IC-tools is to be able to handle and to communicate uncertainty. The stake is to convince participants that the decision process is at least as important as the decision output, because the output will have to be modified in the future due to uncertainty (in accordance with the sustainable development and precaution principles).

\subsection{Impact of IC-tools on PP and SL}

3.2.1. The sharing of informational resources among the participants

A first issue concerns the analysis of the allocation of IC-tools resources (tools, skills, facilitators, training, data, information, time, money) among the participants during the RBM PP process. We assume that a certain degree of equality 
among the parties concerning their informational resources is necessary for a credible PP process. A related point is to analyse whether there is a gradual emergence of formal or informal agreements between stakeholders concerning the sharing of resources to participate, as an indicator of SL.

\subsubsection{Influence of IC-tools on the relational quality among} the participants

Our assumption is that IC-tools can improve the communication between the participants at different organisational scales (within a working group, between working groups, be- tween a representative and his constituencies, between the pro- ject team and the general public, between institutions) by making explicit the social and environmental dimensions of the context.

Another point is that some IC-tools or some specific tasks related to a tool may help to share the same language or to understand each other or at least, to make explicit the differences between the representations of the participants (i.e. thesaurus, database dictionary, cognitive maps, etc.).

Our last assumption is that participating in the co-design of an IC-tool facilitates the acknowledgement of both expert and local knowledge and offers a positive context for bi-directional communication and mutual understanding. A distinction has to be made between tools that are imposing and structuring certain interaction characteristics, and tools that leave more freedom among participants.

\subsubsection{Influence of IC-tools on the technical quality}

of the PP process outcomes

The assumption is that IC-tools may help the involved actor network to better resolve the substantive river basin issues through different ways:

by improving the amount and quality of knowledge on the river basin thanks to better access to information, to a mutual enrichment between expert and local knowledge;

by allowing to test more alternatives during the "search of solutions" phase;

by allowing a better ranking of alternatives (e.g. through the multi-criteria analysis process);

by integrating better the different components of a complex river basin system (e.g. models able to link surface and subsurface water issues, etc.).

The interest of co-designed activities developed in the previous section is still relevant for the technical quality issue.

We also expect that the quality of the relations among the actors is reflected in an enhanced quality and satisfaction with the technical outcomes of the process; and the other way around: the better the joint technical solutions, the more the actors get motivated to invest in their mutual interactions.

\subsection{Perceived usability of IC-tools}

By perceived usability, we refer to the degree to which the user expects the tool to fit a given purpose in a given context (characteristics of the physical, organisational and social environment).

Four components of usability have been selected:

the learnability: amount of things that have to be learnt before using a tool;

the effectiveness: accuracy and completeness with which users achieve specific goals;

the efficiency: amount of resources consumed in performing a task.

the satisfaction: users' subjective reactions in performing a task (absence of discomfort, positive attitudes towards the use).

The perceived usability predicts "attitude towards using" the tool, defined as the user's desirability of her or his using the system. This attitude itself influences the individual's behavioural "intention to use the tool".

People perceive the usability of a tool through indirect sources ('peers' or champions opinions, technical documentation) or practical experiences. In this second case, the level of usability for a given tool will depend on its performances to fulfil a substantive and/or relational task in a specific context. This will influence the decision to use or not to use these IC-tools again in the future.

\section{Early findings from two case studies}

\subsection{Presentation of the case studies}

This paper is based on the analysis of two HarmoniCOP project case studies: French and Flemish cases.

The Dordogne river basin was chosen because public participation to water management was specifically developed at the beginning of the 1990s and so constitutes a particularly interesting and "historical" case for the French context (Barraqué et al., 2004; Raymond et al., 2004). The Dordogne river basin is located in southwest France, covering 24,000 km². Above one million people live in this basin. Presently, the major water uses are hydroelectricity (more than 50 reservoirs), agriculture (irrigation), tourism (various watersports and fishing). Several ecosystem improvement public programs are ongoing. In the 1980s sand and gravel extraction from the riverbed became a serious public concern. So water related problems generally concern all the local communities, and are subject to conflicts requiring political intervention: e.g. in drought periods, to decide and implement water uses restrictions; or in case of floods (alarms, damage coverage), or to answer collective protests against heavy sand and gravel extraction, and increasingly against hydroelectricity water discharges. Created in 1991 by the councils of the départements crossed by the Dordogne, a territorial institution, EPIDOR (Etablissement Public Interdépartemental du bassin de la DORdogne), is in charge of general interest actions concerning water management. It organises co-ordination and consensus building between stakeholders, public communication, creates a data bank; finances specific studies or supports local management actions as river contracts. 
The Flemish case (Craps and Prins, 2004) concerns a tributary of the Scheldt basin $\left(1910 \mathrm{~km}^{2}\right)$, covering $36 \mathrm{~km}^{2}$. This case study is based on a development planning initiative of

a river valley in Flanders. The Environment Administration took this initiative after a severe flooding event in the valley by the end of the former century. The main issues are flood prevention and nature conservation, but other interests as agriculture, recreation (hunting and angling, weekend housing, etc.), drinking water supply, and industry are taken into account. Although the planning initiative of this study is not situated on catchment level but on the more restricted area of the valley, there is a co-ordination with the WFD-based catchment

planning which is currently also in execution.

Both teams carried out an "active observation", through interviews, participative observation in meetings, review of local public and private archives; and pursued interaction with stakeholders in the case study writing phase.

For the French case, a specific ex-post analysis of different water management (or participation) processes was performed at the whole basin level $\left(1054 \mathrm{~km}^{2}\right)$ or at a sub-basin level $\left(610 \mathrm{~km}^{2}\right)$. The research team had also observed the first phase of the implementation of the WFD in real time. The reference documents are the press, web sites, and books about the Dordogne river. The field data were collected from March to December 2004 through 30 interviews with stakeholders and participative observation of two meetings. Results of the observations were presented during five face-to-face meetings and one plenary meeting. For the Flemish case, only a real-time analysis was performed, six months after the start of the process, and has lasted one year (from October 2003 to October 2004). Relevant documents (e.g. progress reports, strategic notes on communication, 17 in total) written by the leading actors were analysed. A total of 25 interviews were carried out with the leading actors, and with stakeholder representatives, hunters, local authorities. The Flemish team made participative observations during interaction moments between different actors where 'things were happening' (10 meetings both formal and informal).

In both cases, the active observation had no influence on the participation process itself. The first results presented in this paper describe the "ordinary" use of IC-tools.

\subsection{IC-tools characteristics and usage situation}

The list of IC-tools that were effectively used (see Table 2)

is very limited compared to the ones given in Table 1 .

The most widely used IC-tools remain very traditional: maps, GIS, questionnaires, etc. After this inventory was taken, we analysed when and for which purpose the IC-tools have

been used (see Table 3). Some differences between the two cases can indeed be distinguished.

In France, questionnaires were widely used (several thousands) to test a draft document, to collect opinion, knowledge and to elicit solutions, during the starting organisation phase in
Table 2

List of IC-tools used in the French case $(\mathrm{F})$ and in the Flemish case (B)
Artefacts/devices

- Questionnaire F, B

- Maps, photos, images F, B

- 3D scale model F

- Cognitive mapping tool $\mathrm{F}$

- Others:

"Léon the sturgeon" $F$
Info System/software

- GIS F, B

- Scenario tool B

- Simulation tool B

- Spreadsheet F

- DSS B

- Internet:

Web information $\mathrm{F}$ questionnaires were used in face-to-face interviews and so were a support for interaction.

In France as in Flanders, "classical" maps were used for visually representing the results of the modelling process (for instance, flood hazard mapping), or of a diagnosis (for instance, ecological indicators). In France, EPIDOR encouraged a sociological study of the actor perceptions of the water releases and their impact. Then, the maps representing these perceptions were used as references for making a shared reality explicit during the problem-solving process.

We also noticed that GIS were omnipresent in all the phases of the process in France as in Flanders, either directly or through map production.

To evaluate and predict floodings, the two main Flemish actors were already using their own simulation models (combined hydraulic and ground water models). A DSS was also available to support visioning process. Developed by the Institute for Nature Conservation, it allowed assessment of the consequences of different measures on ecological indicators. The French actors plan to develop the use of this kind of tool. At present, they use spreadsheets to visualise the evolution of the hydrological regime. Spreadsheets are not easily modifiable by the public or by the stakeholders, and even if they give a precise description, they have been contested by some actors.

The Web site of Epidor (http://www.eptb-dordogne.fr/accueil/accueil.php) has got very simple functions: it provides access to documents and information and gives a list of contacts. The Flemish authorities put the provisional results of their study on a website in its original technical format, which

Table 3

Main functions of IC-tools effectively used

$\begin{array}{llll}\text { Information \& } & \begin{array}{l}\text { Interaction } \\ \text { support }\end{array} & \begin{array}{l}\text { Perspectives } \\ \text { elicitation }\end{array} & \text { Simulation } \\ \text { knowledge } & & \end{array}$

management

French

$\begin{array}{lll}\text { Questionnaire } & \text { Maps } & \text { Questionnaire } \\ \text { Maps } & \text { Léon } & \\ \text { Spreadsheet } & \text { 3D model } & \text { Maps } \\ \text { GIS } & & \text { GIS }\end{array}$

Flemish

Questionnaire Questionnaire DSS Maps Simulation 
1991. The synthesis of these questionnaires was widely disseminated (3000 copies) and allowed to create a shared vision of the existing problems and possible solutions. In Flanders, 
was only accessible for those actors directly involved in the joined planning process.

In France, an original artefact, used in public events, "Léon l'Esturgeon" a 2-m long 3D resin model of a sturgeon, is typically an efficient tool to support interaction with public and to encourage discussion. The same objectives were aimed with the 3D model, but this artefact "speaks" by itself and did not encourage discussion between public and technicians.

For the French case, the IC-tools belong mainly to the stakeholder in charge of the water management and the animation (EPIDOR). For the Flemish case, the tools belong to different public administrations, or to the private consultants in charge of the study and of developing IC-tools as part of their task for which they are hired.

In the Flemish case it was only in the course of the project that models (integrating surface and underground water) were developed enough for the scenario analysis that could evaluate the possible impact of certain interventions that the Nature Administration hoped to realise in the river valley. The first analysis did not confirm the rather optimistic expectations of the public officers in charge of the planning initiative, regarding the positive impact of "giving natural space to the river" on the flooding risks. They were afraid of strong public resistance due to the uncertainties inherent in their nature conservation plans, compared to the "dam up and control" approach of the rivalling Navigable Waterways administration. Therefore they were not very willing to involve the public in their search for alternative intervention scenarios that could reconcile flooding prevention with nature conservation.

\subsection{Impact of IC-tools on SL}

The sharing of informational resources can influence the boundaries that exist in multi-party participatory management processes in river basin management.

In France, water actors have developed over a long time collaborations at national, regional and local levels to federate data about water, relying on a pyramidal architecture. Up to now, these kinds of "informational" boundaries were rather well established. At the national level, all the data are aggregated, standardised and centralised in a national network. In the Adour-Garonne hydrographic district, the Water Authority plays a central role by collecting and managing its own data (respecting the technical national specifications and contributing to the national network), but also by providing financial support and geographic reference data to local river basin observatories, including the one managed by EPIDOR for the Dordogne river basin. EPIDOR in its turn developed partnerships with local authorities or professional associations for data exchange. The technical staff of these institutions meet and collaborate in formal or informal working groups at different levels. The Water Authority tries as much as possible to stick to national and international recommendations and policies (i.e. Aarhus convention), producing highly qualified data and indicators that are comparable at national and European levels. Conversely, EPIDOR has adopted a patrimonial approach. All the data, documents, field observations and local knowledge are archived in a large and multi-form knowledge base, whatever their format or quality. Furthermore, both institutions have produced important efforts to elaborate and disseminate synthetic documents to support decision making (atlas, thematic studies, river basin monographs, etc.). Both of them try also to integrate continually new mature technologies (GIS, Web, Web mapping, etc.) to improve their services. These activities related to information and communication strengthen EPIDOR's position and legitimacy at the river basin level. But preliminary findings reveal that the implementation of the WFD may strongly impact in the coming years these historical "informational" boundaries. The strict and ambitious recommendations of the WFD for reporting activities (Working Group GIS, 2002) have incited the French Water Authorities to carry out a general reflection at the national level in terms of water observatories, data management and data processing (Lalement and Lagarde, 2005). A positive impact is that the current centralised information system architecture will probably shift towards a distributed one, relying more on local actors, qualified to collect specific data. It will enlarge the network of actors involved in data collection and management related to river basins. Conversely, due to financial limitations, the district Water Authorities will condition their financial support to local data managers which respect the terms or reference imposed by the WFD reporting format. To continue getting a financial support from the Water Authority and being a major "informational" actor, EPIDOR will have either to redirect its original information and communication strategy or to find additional funding to maintain it in addition to its new activity related to the WFD. Since the national authorities want the data gathered during the initial phase of the WFD to become the core of the new national water information system, another risk is that the underlying data model defined by the European GIS working Group might turn out to be a dominant "technocratic" frame to represent a river basin system. If for financial or time restriction reasons, the district Water Authorities do not associate with the local actors to build up and validate in a collective way the initial representation of the river basin, some actors may contest it and/or withdraw from the participative process. Another possible consequence is that the procedures to check and describe data quality may delay the dissemination of information. A compromise between data quality and their availability will have to be found in the future, in particular by distinguishing data used for reporting and those used to support local participative processes. In this second case, all the data and local knowledge should a priori be accepted, at least in a first round. Once compared with the shared reality, these data could be used to enhance trust and to maximise the amount of knowledge available to understand the complexity of the river basin system.

Another point concerns the asymmetries in term of IC-tools, information and expertise between the actors, which risk creating a technocratic hierarchy, generating institutional rivalries and reducing the involvement of other parties. For instance, in the Flemish case each of two rivalling Administrations developed its own modelling software as a strategic weapon to capture authority over the river. In the Dordogne, we observed a similar emerging phenomenon of technocratic 
leadership competition because the Water Authority was starting to use a sophisticated hydraulic model to be able later to simulate different scenarios for the WFD.

From a SL perspective, one of the major challenges consists in framing in such a way that a convergence of views becomes possible through interaction and collective learning processes. In the Dordogne, a specific approach played a pivotal role and contributed to modify the participants' frames on the conflictual water releases issue, caused by EDF dams for hydroelectricity production. The working group in charge of finding solutions commissioned for the first time, in addition to hydrological studies, a sociological study to analyse users' perceptions of the water releases and their consequences (Faure, 2000). The inquiry was conducted by an experienced anthropologist who was attentive to the local knowledge and concerns of the river users (fishermen, water sports and tourist activities, environmental associations). This expert produced several maps illustrating the impacts of water releases, as perceived by the users. These maps, which were presented during a plenary meeting, had a strong impact on the participants. They assured the actors affected by water releases that the impacts on their activities were placed on the table in a very visible and collective way. They also provided evidence that actors framed the problem differently and for the first time they gave an integrated representation of water release phenomena all along the river. Finally, they helped EDF to increase its awareness of the social impacts of its dams. Other IC-tools helped participants to understand better the physical phenomenon of water releases, which had remained ill defined and contested by some actors until then. The graphs showing the flow/time relationship made the knowledge on flows accessible for all and they attested the change in the hydrological regime. Field trips and video sessions organised by fishermen's associations allowed all participants to see the impact of water releases on fish reproduction. For its part, EDF also developed tools to communicate its vision about water management. A permanent exposition of these tools was installed in one of EDF dams: a 3D model of a hydro-electric dam, a 2.5D chart localising all the dams on the Dordogne river, video cassettes and measuring instruments, which testify that EDF cares about people's safety. These communication tools are offering a public image of EDF, which emphasises the rational dimension of dam and water release management. Other actors became more aware of the requirements of hydro-electricity production, as a part of the national and even European energy policy and market. All these tools contributed to a collective reframing of the phenomenon and to a convergence of different viewpoints.

The tools also contributed towards changing the boundaries of the problem. The collective perceptive maps allowed to modify the understanding of the area affected by the water releases: it was no longer a local issue close to the dams but a much larger one, all along the river (and even on a national and European scale). Consequently, they also strengthened the legitimacy of actors that were previously considered marginal or external to the issue.

Another major finding in both case studies is that the way IC-tools were introduced and used in the participative process was as important as their functionalities and their informational content. A good example is the development of a GIS, generally perceived as a high-tech tool, on the Cère river in France The data stored in the GIS were collected in a very visible way at the start of the participation process. A representative from the authority spent several weeks making a local inventory of the weirs and mapping of ecological habitats along the stretch of river at moments when she was likely to be seen by the local people. She invited them to comment on what she was doing, and it was part of her task to explain her role in data gathering. Data were collected and presented by maps and field pictures were introduced within the GIS so that stakeholders could gain a better understanding of issues within the river basin and could make a better link with their perceived reality. This GIS database was a useful tool in itself, but especially the way it was generated had as a consequence that stakeholders could more easily link what the GIS database was telling them to their own understanding of their environment. They also valued the GIS database more highly because they had seen the efforts made by the local authority in its development, and this helped to build trust between stakeholders and the institution. This approach enforced the legitimacy of the woman who performed the task and allowed her to better diffuse the technical knowledge. Conversely, in the Céou river case, the local authority decided to contract an engineering company to perform a hydrologic study in a conflictual context. This company mobilised a well-qualified hydrologist who, unaware of the on-going conflicts, did not visit the area himself but rather employed young staff to do it. When he had to present his results, stakeholders objected that he had not incorporated their own knowledge and that he had not done any fieldwork. These two different cases illustrate the need to build up the scientific and technical information required for integrated water management in constant interaction with the learning process as it takes place between the stakeholders. The co-design of an IC-tool can contribute to this issue.

\subsection{Perceived usability}

As there were no specific efforts either in Flanders or France to explore and reflect on new possibilities for IC-tools to enhance two-way communication among the actors, tools were generally inserted in the process for usual and technical uses: to diagnose and eventually to communicate in a one-way direction. Although it is still too early to formulate wellgrounded conclusions., one clear lesson dealing with the degree of sophistication of the tools can already be drawn. Even if high-tech tools satisfy their operator, strengthen the technical leadership of some institutions or bring a real added value especially to simulate complex phenomena, most of the stakeholders call for simpler communication tools, which are able to make the information more accessible to a wide range of audiences. For instance, in Flanders, according to some actors a television documentary contributed most significantly to an increased understanding and a positive image of the river valley (Craps and Prins, 2004). Sometimes, a site visit or a field 
trip may be very helpful to complement for example a complex hydraulic modelling, showing in a concrete setting to which level the water may rise after a specific proposed intervention. Simple maps proved to be very efficient intermediary objects to bring the actors together and to gather local knowledge.

The use of a variety of formal and informal interaction possibilities and of IC-tools, to present technical information in different ways, may make a joint planning process more accessible to a wide range of stakeholders. By this way the technical information supports local actors to explore and clarify their own understanding of the river basin. But IC-tools, either poorly designed or used inadequately, for example with too much technical content, can act as a barrier to SL, by overwhelming actors with technical information which is not relevant or understandable for them (Tippet et al., 2005).

\section{Perspectives}

The preliminary findings presented in this article will be validated and completed with the results from other HarmoniCOP case studies. Their analysis will shown in a more systematic way which IC-tools have been used, their usage situation and the relational as well as substantive outputs as perceived by the users and by the HarmoniCOP researchers. The case studies will assess the gap between the potentials of the tools, the current uses and the perceived usability. Preliminary findings seem to confirm the gap already observed in Flanders and France case studies between all the efforts in tool development as described in literature and the tools effectively used in RBM. We will update our preliminary qualitative categorisation of IC-tools according to these results. A cross-case comparison will also contribute to a better understanding of the economical, technical, institutional and cultural factors that might affect the usability of IC-tools. Finally, the case studies will allow to verify our hypothesis on the importance of sharing informational resources and of co-designing IC-tools.

Our major expectation is to be able through these findings to make more explicit the relational functions of the IC-tools and their impact on SL. A second expectation is to make practical recommendations for tools developers (e.g. new design criteria, new functionalities, etc.) to increase their use in RBM.

Another more practical perspective concerns the production of a handbook on SL for RBM. It will allow the WFD practitioners to tailor a participatory RBM process to local/regional conditions. Concerning IC-tools, the handbook will help the SL facilitators to answer concrete questions such as: What are the relational and substantive functions of a tool? How should it be used? Which resources and skills are required? What is its applicability in the different phases of the PP process? When was it used and who might be contacted for additional information?

HarmoniCOP considers this handbook as a means to make the SL concept "learning together to manage together" more accessible to water managers and to support its putting into practice.

\section{Acknowledgements}

This paper is based on research that is being carried out as part of the HarmoniCOP project conducted under financial contribution of the European Commission (contract no. EVK1-CT-2002-00120). The authors would like to thank the European Commission, who funded the HarmoniCOP project, the Flemish and French stakeholders that have been involved in the case studies, and the colleagues that have been involved in the project, especially those who contributed to Work Packages No. 2 'Social Learning', 'No. 3 'Role of Information and Communication Tools' and No. 5 'National case studies'. Further information can be found on the project web site http:// www.harmonicop.info.

\section{References}

Arnstein, S., 1969. A ladder of citizen participation in the USA. Journal of the American Institute of Planners 216e224.

Barraqué, B., Le Bouhris, J.P., Maurel, P., Raymond, R., 2004. Public participation in the Dordogne river basin. Case study report produced under work package 5 of the HarmoniCOP project, Bruxelles, Belgium.

Craps, M. (Ed.), 2003. Social Learning in river basin management, WP2 report of the HarmoniCOP project, Bruxelles, Belgium.

Craps, M., Maurel, P. (Eds.), 2003. Social Learning Pool of Questions. An instrument to diagnose Social Learning and IC tools in European river basin management, combined WP2/WP3 report of the HarmoniCOP project, Bruxelles, Belgium.

Craps, M., Prins, S., 2004. Participation and Social Learning in the development planning of a Flemish river valley. Case study report produced under work package 5 of the HarmoniCOP project, Bruxelles, Belgium.

Craps, M., Dewulf, A., Mancero, M., Santos, E., Bouwen, R., 2004. Constructing common ground and re-creating differences between professional and indigenous communities in the Andes. Journal of Community and Applied Social Psychology 14, 378e393.

Dewulf, A., Gray, B., Putnam, L., Aarts, N., Lewicki, R., Bouwen, R., van Woerkum, C., 2005. Disentangling approaches to framing: mapping the terrain. Paper Submitted for 18th IACM Conference, Sevilla, Spain.

Drafting Group, 2002. Guidance on public participation in relation to the Water Framework Directive e active involvement, consultation, and public access to information. EC report, Bruxelles, Belgium.

Faure, A., 2000. Etude de l'impact social des éclusées sur les vallées de la Dordogne, la Cère, la Maronne et la Vézère. EPIDOR report, Bergerac, France.

Ferrand, N., Cernesson, F., Maurel, P., June 14e17, 2004. Comparative charting of IC tools usage in Social Learning processes. International Environmental Modelling and Software (iEMSs) Conference. Osnabruck, Germany.

Fisker, J., 1990. Introduction to Communication Studies, second ed. Routledge, London-New York.

Lalement, R., Lagarde, P., 2005. Architecture du Système d'Information sur l'Eau. Livre Vert. Ministère de l'Ecologie et du Développement Durable, Paris, France.

Legris, P., Ingham, J., Collerette, P., 2003. Why do people use information technology? A critical review of the technology acceptance model. Information and Management 40, 191 e204.

Lewicki, R., Gray, B., Elliot, M., 2003. Making Sense of Intractable Environmental Conflicts. Island Press, Washington.

Maurel, P. (Ed.), 2003. Public participation and the European Water Framework Directive. Role of information and communication tools, WP3 report of the HarmoniCOP project, Bruxelles, Belgium.

Mostert, E., 2003. The challenge of public participation. Water Policy 5, 179 e 197.

Pahl-Wostl, C., 2002. Participative and stakeholder-based policy design, evaluation and modeling processes. Integrated Assessment 3, 3e14. 
Raymond, R., Maurel, P., Ferrand, N., Barreteau, O., 2004. Quelles fonctions et quels usages pour les outils d'information géographique dans la gestion durable des hydrosystèmes continentaux? In: Scarwell, H.-J., Frenchomme, M. (Eds.), Contraintes environnementales et gouvernance des territoires. Editions de l'Aube: La Tour d'Aigues, France, pp. 435 e 443.

Star, S.L., Greisemer, J.R., 1989. Institutional Ecology, "Translations" and boundary objects: Amateurs and professionals in Berkeley's museum of vertebrate zoology. Social studies of Science 19, 387e420.

Tippet, J., Searl, B., Pahl-Wostl, C., Rees, Y., 2005. Social Learning in public participation in river basin management e Early findings from HarmoniCOP European case studies. In: Environmental Science and Policy, vol. 8. Research and technology integration in support of the European Union Water Framework Directive, Bruxelles, Belgium. Special issue, issue 3.

Ubbels, A., Verhallen, J.M., 2000. Suitability of Decision Support Tools for Collaborative Planning Processes in Water Resources Management. RIZA: Wageningen University, Netherlands.
Vinck, D., Jeantet, A., 1995. Mediating and commissioning objects in the sociotechnical process of product design: a conceptual approach. In: MacLean, D., Saviotti, P., Vinck, D. (Eds.), Management and New Technology: Design, Networks and Strategy. COST Social Science Series. Bruxelles, Belgium.

Webler, T., Tuler, S., Krueger, R., 2001. What is a good public participation process? Five perspectives from the public. Environmental Management 27 (3), 435e 450

Wenger, E., 1998. Communities of practice. Learning, Meaning and Identity. Cambridge University Press, Cambridge, England.

Woodhill, A.J., 2004. Dialogue and transboundary water resources management: towards a framework for facilitating Social Learning. In: Langaas, S., Timmerman, J.G. (Eds.), The Role and Use of Environmental Information in European Transboundary River Basin Management. IWA, London, England.

Working Group GIS, 2002. Guidance document on implementing the GIS elements of the WFD. EC report: Bruxelles, Belgium. 